\title{
Research on Fuzzy Comprehensive Evaluation of Transmission and Transformation Project Based on Analytic Hierarchy Process
}

\author{
Shuliang Liu ${ }^{1, a}$ and Yijing Liang ${ }^{1, b}$ \\ ${ }^{12}$ School of Economics and Management, North China Electric Power University, Baoding, 071003, \\ Hebei, China \\ a123IsI@163.com, blyj349041396@126.com
}

Keywords: Power transmission engineering; Analytic hierarchy process; Index system; Weight; Fuzzy comprehensive evaluation

\begin{abstract}
The establishment of a power transmission project needs to take into account the technical, economic and social benefits and so on, these factors affect each other, which is difficult to accurately distinguish and define. In this context, a method of combining AHP and fuzzy comprehensive evaluation is proposed. Firstly, the evaluation index system is established, and the weight of each evaluation factor is determined by AHP. Then, the fuzzy comprehensive evaluation model based on AHP is constructed to carry on the comprehensive evaluation and analysis. Finally, The application of the example in the substation project confirms that the model is scientific and feasible.
\end{abstract}

\section{Introduction}

The development of electricity plays an important role in the improvement of China's economic development, national security, social stability and the quality of life of the people. The construction of $220 \mathrm{KV}$ power transmission project can increase the regional power supply capacity and improve the quality of power supply in the region. With the improvement of regional power supply capacity and power supply quality, the normal production of local enterprises will have power supply protection, which can provide the basic conditions for expanding the scale of production, so as to play a positive role in regional economic development.

The comprehensive evaluation of the project refers to a kind of technical and economic activities which systematically analyze and objectively summarize the purpose, the implementation process, the benefit, the effect and the influence of the project. The comprehensive evaluation of project can determine whether the expected target of the project is achieved and whether the main benefit index is realized. At the same time, it can find the reasons for the success of the project, summarize the lessons learned, timely and effectively feedback the information, improve the management level of the new project in the future and achieve the purpose of improving the investment benefit [1].

Based on the general theory and method of comprehensive evaluation of project, this paper constructs a comprehensive evaluation model of power transmission and transformation project. Based on the actual investigation and analysis, this paper constructs the evaluation index system, including technical indicators, economic benefit index and social factors, and uses the analytic hierarchy process to determine the weight. Then through the fuzzy comprehensive evaluation method for quantitative analysis of various factors, in view of which can carry out comprehensive evaluation of power transmission project. A empirical example shows that the model can achieve good evaluation results. 


\section{Theoretical Basis}

Analytic Hierarchy Process. The Analytic Hierarchy Process (AHP) was developed by Professor Sartre of the University of Pittsburgh, which is a complex decision for multiple selection criteria. It divides the complex decision-making situation into several small parts, and then organizes them into a tree-like hierarchy. Then, the relative importance of each part is given the weight value, and then the priority of each part is analyzed. For decision makers, it is very helpful to organize the selection criteria, weights and analysis of the alternatives in a hierarchical structure [2]. The specific construction steps are:

First, the Establishment of Hierarchical Model

It can usually be divided into a hierarchical model as shown in Fig. 1.

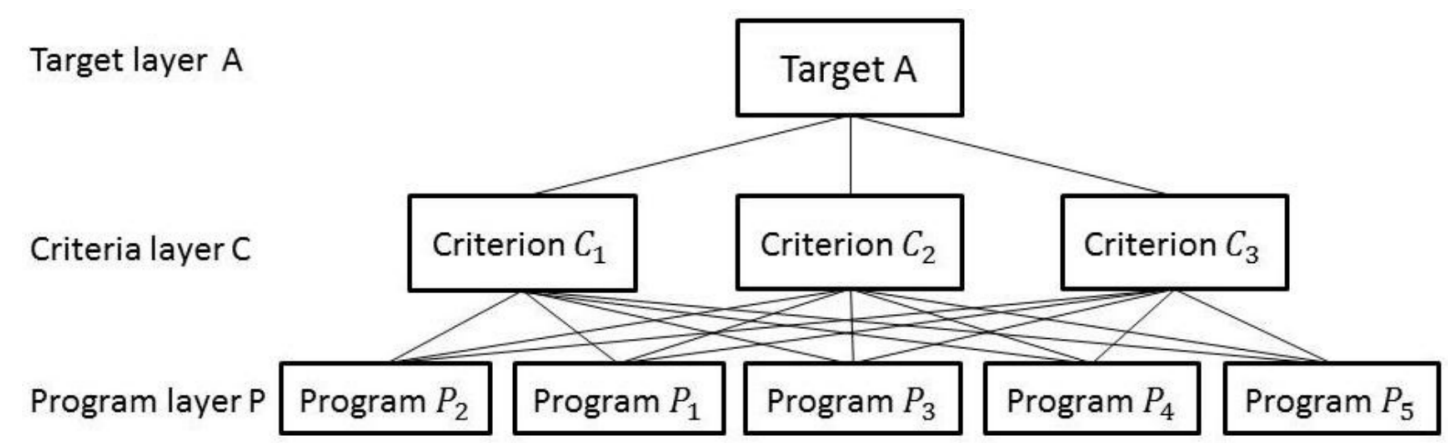

Figure 1. Hierarchical model

Second, the Construction of Judgment Matrix

The judgment matrix represents the relative importance of the factors associated with this level for a factor of the last level. Assuming that the factor $A_{k i n}$ the A layer is related to the factors B1, $\mathrm{B} 2, \ldots \mathrm{Bn}$ in the next hierarchy, the judgment matrix constructed is shown in Table 1.

Table 1 Judgment Matrix

\begin{tabular}{c|cccc}
\hline Ak & B1 & B2 & $\ldots$ & Bn \\
\hline B1 & b11 & b12 & $\ldots$ & b1n \\
B2 & b21 & b22 & $\ldots$ & b2n \\
$\ldots$ & $\ldots$ & $\ldots$ & $\ldots$ & $\ldots$ \\
Bn & bn1 & bn2 & $\ldots$ & bnn \\
\hline
\end{tabular}

In Table 2-1, $b_{i j}$ is a numerical representation of the relative importance of $B_{i}$ to $B_{j}$ for $A_{k}$, usually $\mathrm{b}_{i j}$ take $1,2,3, \ldots, 9$ and their reciprocal, the meaning is shown in Table 2. 
Table 2 Scale

\begin{tabular}{cl}
\hline Importance scale & \multicolumn{1}{c}{ meaning } \\
\hline 1 & $\begin{array}{l}\text { The two elements are just as important } \\
\text { The former is slightly more important } \\
\text { than the latter } \\
\text { The former is obviously more important } \\
\text { than the latter } \\
\text { The former is mightily more important } \\
\text { than the latter } \\
\text { The former is extremely important than } \\
\text { the latter } \\
\text { The intermediate value of the } \\
\text { corresponding 1-9 scale }\end{array}$ \\
\hline
\end{tabular}

Third, the hierarchical single order

By judging the weight of order of importance of the factors associated with this factor in relation to a factor of the upper layer. The hierarchical single order can be summed up as the characteristic root and eigenvector problem of the judgment matrix, that is, the judgment matrix $B$, whose value of the eigenvalue and the eigenvector satisfies:

$$
\mathrm{BW}=\lambda_{\max } W
$$

In the formula, $\lambda_{\max }$ is the largest eigenvalue of $\mathrm{B} ; \mathrm{W}$ is the normalized eigenvector corresponding to $\lambda_{\max }$, the component $W_{i}$ of $\mathrm{W}$ is the weight of the single factor of the corresponding factor.

In order to test the consistency of the matrix, it is necessary to calculate its consistency index CI, which is defined

$$
\mathrm{CI}=\frac{\lambda_{\min }-n}{n-1} \text {. }
$$

Obviously, when the judgment matrix has complete consistency, $\mathrm{CI}=0$. The larger the $\lambda_{\max }-\mathrm{n}$ is, the larger the $\mathrm{CI}$ is, the worse the consistency of the matrix is. In order to test whether the judgment matrix has satisfactory consistency, it is necessary to compare the CI with the average random consistency index RI. For the 1-9 order matrix, RI is shown in Table 3, respectively.

Table 3 Average randomness of the 1-9 order matrix

\begin{tabular}{cccccccccc}
\hline Order & 1 & 2 & 3 & 4 & 5 & 6 & 7 & 8 & 9 \\
\hline RI & 0.00 & 0.00 & 0.58 & 0.90 & 1.12 & 1.24 & 1.32 & 1.41 & 1.45 \\
\hline
\end{tabular}

For the first order and the second order judgment matrix, RI is only formal, and according to our definition of the judgment matrix, the first order, second order judgment matrix is always exactly the same. When the order is greater than 2, the ratio of the consistency index CI of the judgment 
matrix to the RI of the same order average randomness index is called the stochastic consistency ratio of the judgment matrix, recorded as CR.

$$
\mathrm{CR}=\frac{C I}{R I}<0.10
$$

Judgment matrix has a satisfactory consistency, otherwise it is necessary to adjust the judgment matrix.

Last, consistency Test

In order to evaluate the consistency of the results of the overall ranking of the hierarchy, it is necessary to calculate the amount of tests which is similar to the single order. CI is the consistency index; RI is the mean random consistency index; CR is the random consistency proportion. Their expressions are:

$$
\mathrm{CI}=\sum_{\mathrm{i}=1}^{\mathrm{m}} a_{i} C I_{i}
$$

In the formula, $\mathrm{CI}_{i}$ is the consistency index of the judgment matrix in the B corresponding to $a_{i}$

$$
\mathrm{CI}=\sum_{\mathrm{i}=1}^{\mathrm{m}} a_{i} R I_{i}
$$

In the formula, $\mathrm{RI}_{i}$ is the mean random consistency index of the judgment matrix in the $\mathrm{B}$ corresponding to $a_{i}$

$$
\mathrm{CR}=\mathrm{CI} / \mathrm{RI}
$$

$$
\text { If, }
$$

$$
\mathrm{CR}<0.10
$$

Then, the results of the total ranking are satisfactory.

Fuzzy Comprehensive Evaluation. Fuzzy comprehensive evaluation can be used to carry out a comprehensive, correct and quantitative evaluation of people, things and things in public management. For example, the evaluator consider the problem from the various factors, with reference to the relevant data and circumstances, and according to their judgments on the issue, separately make "big, medium, small", "high, medium, low", "excellent, good, middle, bad "," good, better, general, poor "and other levels of fuzzy evaluation. Through the fuzzy mathematics method of operation, we can get a quantitative comprehensive evaluation results, so as to provide a reference for the correct decision [3].

If the evaluation index is $\mathrm{n}$, denoted as $u_{1}, u_{2}, u_{3, \ldots}, u_{m}$, then these evaluation factors constitute a finite set of evaluation factors called $\mathrm{U}$ :

$$
\mathrm{U}=\left\{u_{1}, u_{2}, u_{3}, \ldots, u_{n}\right\}
$$

In the light of the actual needs, the comments are divided into multiple levels, respectively, as $v_{1}, v_{2}, v_{3}, \ldots, v_{m}$, and then constitute a limited set of comments called $\mathrm{V}$ : 


$$
\mathrm{V}=\left\{v_{1}, v_{2}, v_{3}, \ldots, v_{m}\right\}
$$

After constructing the hierarchical fuzzy subset, we must quantify the factor from each factor $u_{\mathrm{i}}$ one by one, that is, determine the membership degree $\mathrm{R}$ of the rating fuzzy subset from the single factor, and then get the fuzzy relation matrix:

$$
R=\left[\begin{array}{c}
R_{1} \\
\vdots \\
R_{2}
\end{array}\right]=\left[\begin{array}{ccc}
r_{11} & \cdots & r_{1 m} \\
\vdots & \ddots & \vdots \\
r_{\mathrm{n} 1} & \cdots & r_{\mathrm{nm}}
\end{array}\right]
$$

In the matrix $\mathrm{R}$, the element called $\mathrm{r}_{i j}$ represents the degree of membership of the $\mathrm{v}_{j}$-class fuzzy subset from the factor called $\mathrm{u}_{i}$.

In the fuzzy comprehensive evaluation, the weight vector of the evaluation factor is determined: $\mathrm{A}=\left(a_{1}, a_{2}, \ldots, a_{n}\right)$, the element $a_{i}$ in the weight vector $\mathrm{A}$ is essentially the membership degree of the factor $u_{i}$ to the fuzzy subset. This paper uses the analytic hierarchy process to determine the relative importance order between evaluation indicators, thereby determining the weighting factor and normalizing it before synthesis, which is

$$
\sum_{i=1}^{n} a_{i}=1
$$

Using the appropriate operator, we combine A with each of the evaluated things to obtain the fuzzy comprehensive evaluation result of each subject called vector $\mathrm{B}$, which is

$$
\text { A R }=\left(a_{1}, a_{2}, \ldots, a_{n}\right)\left[\begin{array}{ccc}
r_{11} & \cdots & r_{1 m} \\
\vdots & \ddots & \vdots \\
r_{n 1} & \cdots & r_{n m}
\end{array}\right]=\left(b_{1}, b_{2}, \ldots, b_{m}\right)=B
$$

Where $b_{i}$ is calculated from the jth column of $A$ and $\mathrm{R}$, which indicates the degree of membership of the $v_{j}$ rank fuzzy subset as a whole.

\section{Example Application}

Project Introduction. To meet the growing load demand in the southeastern part of Gaobeidian, strengthen the area $220 \mathrm{kV}$ network structure, improve the reliability of the $110 \mathrm{kV}$ power supply in the region, reduce the power supply pressure of the surrounding $220 \mathrm{kV}$ substation and improve the reliability of the power supply in the north of Baoding, Gaobeidian South 220kV substation is needed to build. This paper takes the Gaobeidian 220V substation construction project as an example to carry on the example analysis.

Analysis and Establishment of Index System. Based on the design principle of the index system and the requirements of the multi-level fuzzy comprehensive evaluation method [4], this paper divides the comprehensive evaluation index system of Gaobeidian South 220V substation construction project into technical index, economic benefit index and social benefit index under the guidance of relevant experts. On this basis, the index structure level is further divided. Technical indicators include: power system once, power system twice, the overall planning and the overall layout of the station, building and structural design, water supply and drainage systems[5]-[7]. Economic performance indicators include: investment estimates, internal rate of return, investment payback period, financial net present value [8]-[9]. Social benefits indicators include: energy saving, environmental protection, disaster resistance [10]-[11]. Specific index system construction is shown in Fig. 2. 


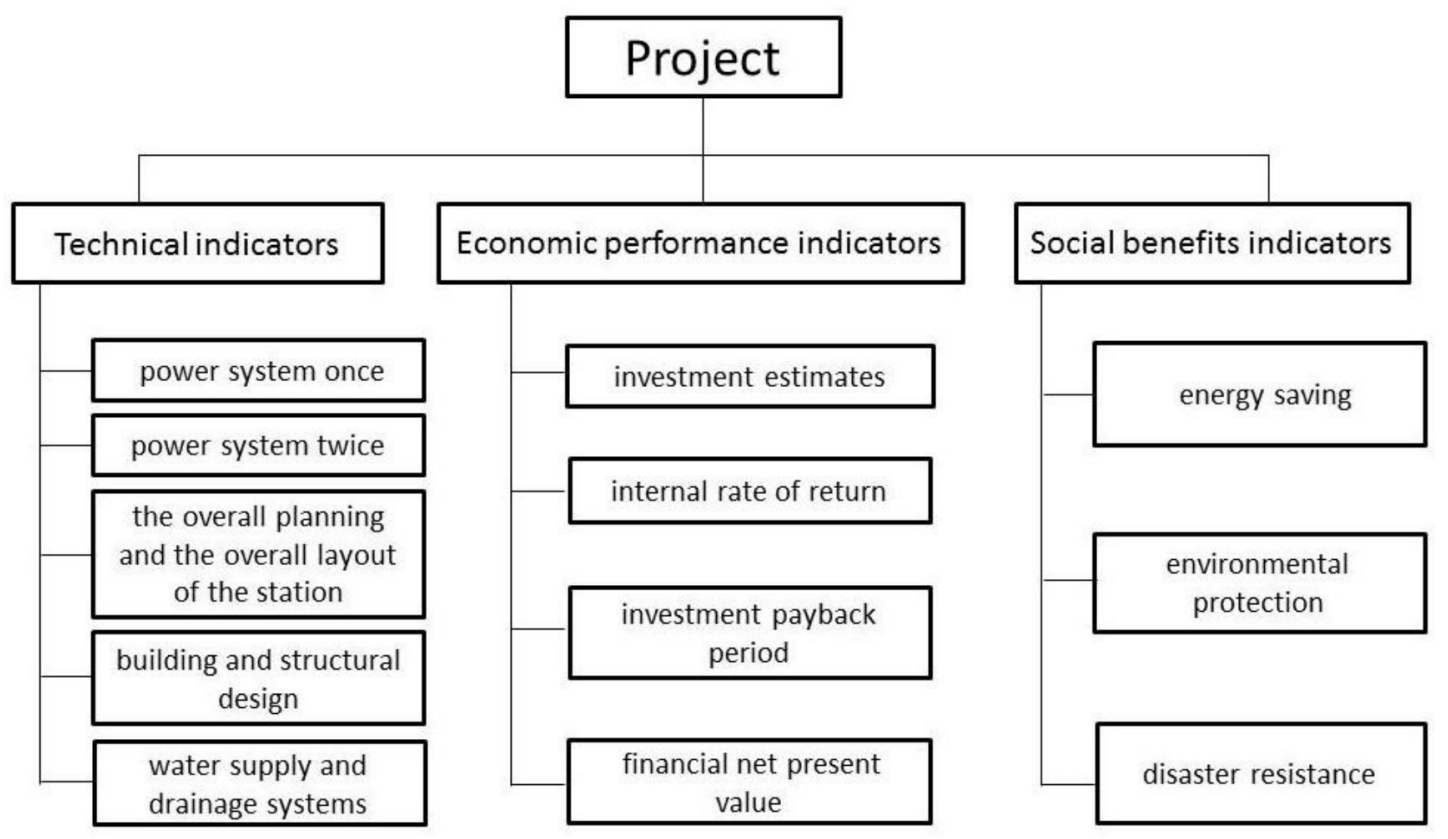

Figure 2. Index System of Substation Construction Project

Determine the Weight. This paper uses the analytic hierarchy process to determine the weight, and combines the expert scoring method to determine the weight of each element by constructing the judgment matrix, the single order of the hierarchy, the total ranking of the hierarchy and the final consistency test. In this paper, we use the ANC to calculate the normalized values of each column of the matrix, and analyze the three aspects.

First, Gaobeidian South 220V Substation Construction Project.

Table 4 Index Weight of Effects Layer

\begin{tabular}{|c|c|c|c|c|}
\hline Project & $\begin{array}{l}\text { Technical } \\
\text { indicators }\end{array}$ & $\begin{array}{l}\text { Economic } \\
\text { performance } \\
\text { indicators }\end{array}$ & $\begin{array}{l}\text { Social benefits } \\
\text { indicators }\end{array}$ & Weights \\
\hline $\begin{array}{l}\text { Technical } \\
\text { indicators }\end{array}$ & 1 & 5 & 3 & 0.634 \\
\hline $\begin{array}{l}\text { Economic } \\
\text { performance } \\
\text { indicators }\end{array}$ & $1 / 5$ & 1 & $1 / 3$ & 0.106 \\
\hline $\begin{array}{c}\text { Social benefits } \\
\text { indicators }\end{array}$ & $1 / 3$ & 3 & 1 & 0.260 \\
\hline \multicolumn{5}{|c|}{$\lambda_{\max }=3.037, \quad \mathrm{CI}=0.0185, \quad \mathrm{CR}=0.0319<0.1$} \\
\hline \multicolumn{5}{|c|}{ Meet the consistency test } \\
\hline
\end{tabular}

Second, technical Indicators. 
Table 5 The Weights of Technical Indicators

\begin{tabular}{|c|c|c|c|c|c|c|c|}
\hline $\begin{array}{l}\text { Technical } \\
\text { Indicators }\end{array}$ & $\begin{array}{l}\text { power } \\
\text { system } \\
\text { once }\end{array}$ & $\begin{array}{l}\text { power } \\
\text { system } \\
\text { twice }\end{array}$ & & & $\begin{array}{l}\text { building } \\
\text { and } \\
\text { structural } \\
\text { design }\end{array}$ & $\begin{array}{l}\text { water } \\
\text { supply } \\
\text { and } \\
\text { drainage } \\
\text { systems }\end{array}$ & Weights \\
\hline $\begin{array}{c}\text { power system } \\
\text { once }\end{array}$ & 1 & & 3 & 5 & 4 & 7 & 0.491 \\
\hline $\begin{array}{c}\text { power system } \\
\text { twice }\end{array}$ & $1 / 3$ & & 1 & 3 & 2 & 5 & 0.232 \\
\hline $\begin{array}{c}\text { Overall } \\
\text { planning and } \\
\text { the overall } \\
\text { layout }\end{array}$ & $1 / 5$ & & $1 / 3$ & 1 & $1 / 2$ & 3 & 0.092 \\
\hline $\begin{array}{l}\text { building and } \\
\text { structural } \\
\text { design }\end{array}$ & $1 / 4$ & & $1 / 2$ & 2 & 1 & 3 & 0.138 \\
\hline $\begin{array}{l}\text { water supply } \\
\text { and drainage } \\
\text { systems }\end{array}$ & $1 / 7$ & & $1 / 5$ & $1 / 3$ & $1 / 3$ & 1 & 0.046 \\
\hline \multicolumn{8}{|c|}{$\lambda_{\max }=5.126, \quad \mathrm{CI}=0.032, \quad \mathrm{CR}=0.028<0.1$} \\
\hline
\end{tabular}

Third, economic Performance Indicators.

Table 6 The Weights of Economic Performance Indicators

\begin{tabular}{|c|c|c|c|c|c|}
\hline $\begin{array}{l}\text { Economic } \\
\text { Performance } \\
\text { Indicators }\end{array}$ & $\begin{array}{l}\text { investment } \\
\text { estimates }\end{array}$ & $\begin{array}{l}\text { internal rate of } \\
\text { return }\end{array}$ & $\begin{array}{l}\text { investment } \\
\text { payback period }\end{array}$ & $\begin{array}{l}\text { financial net } \\
\text { present value }\end{array}$ & weights \\
\hline $\begin{array}{l}\text { investment } \\
\text { estimates }\end{array}$ & 1 & $1 / 7$ & $1 / 3$ & $1 / 5$ & 0.055 \\
\hline $\begin{array}{l}\text { internal rate of } \\
\text { return }\end{array}$ & 7 & 1 & 5 & 3 & 0.564 \\
\hline $\begin{array}{c}\text { investment } \\
\text { payback period }\end{array}$ & 3 & $1 / 5$ & 1 & $1 / 3$ & 0.118 \\
\hline $\begin{array}{l}\text { financial net } \\
\text { present value }\end{array}$ & 5 & $1 / 3$ & 3 & 1 & 0.263 \\
\hline \multicolumn{6}{|c|}{$\lambda_{\max }=4.117, \quad \mathrm{CI}=0.039, \quad \mathrm{CR}=0.043<0.1$} \\
\hline \multicolumn{6}{|c|}{ Meet the consistency test } \\
\hline
\end{tabular}

Last, social Benefits Indicators. 
Table 7 The Weights of Social Benefits Indicators

\begin{tabular}{|c|c|c|c|c|}
\hline $\begin{array}{l}\text { Social } \\
\text { Benefits Indicators }\end{array}$ & energy saving & $\begin{array}{l}\text { environmental } \\
\text { protection }\end{array}$ & disaster resistance & weights \\
\hline energy saving & 1 & 2 & 4 & 0.547 \\
\hline $\begin{array}{c}\text { environmental } \\
\text { protection }\end{array}$ & $1 / 2$ & 1 & 4 & 0.345 \\
\hline \multicolumn{5}{|c|}{$\lambda_{\max }=3.0536, \mathrm{CI}=0.0268, \mathrm{CR}=0.046<0.1$} \\
\hline & & consistency tes & & \\
\hline
\end{tabular}

Fuzzy Comprehensive Evaluation of Single Factor. Because the substation new project is affected by many factors, so this paper uses the fuzzy mathematics knowledge to carry on the comprehensive appraisal to this project. According to the established evaluation index system, this paper establishes a fuzzy comprehensive evaluation model. The factor level is set to U, evaluation level is set to $\mathrm{V}$.

$$
\begin{aligned}
& \mathrm{U}=\left\{u_{1}, u_{2}, u_{3}, u_{4}\right\} \\
& \mathrm{V}=\left\{v_{1}, v_{2}, v_{3}, v_{4}\right\}=\{\text { excellent, good, medium, poor }\}
\end{aligned}
$$

Based on the results determined by 20 experts for each indicator, the single factor evaluation matrix of the substation project was determined.

The Relationship Matrix of Technical Aspects

$$
R_{1}=\left[\begin{array}{cccc}
0.80 & 0.15 & 0.05 & 0 \\
0.75 & 0.20 & 0.05 & 0 \\
0.70 & 0.15 & 0.10 & 0.05 \\
0.65 & 0.20 & 0.10 & 0.05 \\
0.60 & 0.20 & 0.15 & 0.05
\end{array}\right]
$$

The sub-index weight vector is:

$$
W_{1}=\left(\begin{array}{llll}
0.491, & 0.232,0.092,0.138,0.046
\end{array}\right)
$$

The Relationship Matrix of Economic Performance,

$$
R_{2}=\left[\begin{array}{llll}
0.60 & 0.30 & 0.10 & 0 \\
0.70 & 0.20 & 0.10 & 0 \\
0.70 & 0.20 & 0.10 & 0 \\
0.70 & 0.25 & 0.05 & 0
\end{array}\right]
$$

The sub-index weight vector is:

$$
W_{2}=(0.055,0.564,0.118,0.263)
$$

The Relationship Matrix of Social Benefits, 


$$
R_{3}=\left[\begin{array}{cccc}
0.70 & 0.20 & 0.10 & 0 \\
0.60 & 0.30 & 0.05 & 0.05 \\
0.50 & 0.35 & 0.10 & 0.05
\end{array}\right]
$$

The sub-index weight vector is:

$$
W_{3}=\left(\begin{array}{lll}
0.547,0.345,0.109
\end{array}\right)
$$

By using the weighted average algorithm, we can get the membership degree of each factor under the effect layer index,

$$
\begin{aligned}
& \gamma_{1}=W_{1} R_{1}=(0.74850,0.17065,0.06605,0.01380) \\
& \gamma_{2}=W_{2} R_{2}=\left(\begin{array}{lll}
0.69450,0.21865, & 0.08685,0
\end{array}\right) \\
& =W_{3} R_{3}=\left(\begin{array}{lll}
0.64440,0.25105, & 0.08285,0
\end{array}\right)
\end{aligned}
$$

Fuzzy Comprehensive Evaluation. According to the above analysis results, organizing the weight and membership, evaluation matrix A of the effect factor set is:

$$
A=\left[\begin{array}{cccc}
0.74850 & 0.17065 & 0.06605 & 0.01380 \\
0.69450 & 0.21865 & 0.08685 & 0 \\
0.64440 & 0.25105 & 0.08285 & 0
\end{array}\right]
$$

The weight of the effect layer is

$$
\mathrm{W}=\left(W_{1}, W_{2}, W_{3}\right)=(0.634,0.106,0.260)
$$

Then,

$$
\begin{aligned}
& B=A^{0} W=\left[\begin{array}{lllc}
0.74850 & 0.17065 & 0.06605 & 0.01380 \\
0.69450 & 0.21865 & 0.08685 & 0 \\
0.64440 & 0.25105 & 0.08285 & 0
\end{array}\right] \circ(0.634,0.106,0.260)= \\
& (0.71571, \quad 0.196642, \quad 0.0726228,0.0087492)
\end{aligned}
$$

Analysis of Results. The results of the above-mentioned evaluation and the results of the two-level evaluation are shown in Table 8 and Table 9.

Table 8 Evaluation Results of Level 1

\begin{tabular}{ccccc}
\hline Indicator & \multicolumn{5}{c}{ Result } \\
\cline { 2 - 5 } & excellent & good & medium & poor \\
\hline Technical & 0.74850 & 0.17065 & 0.06605 & 0.01380 \\
\hline $\begin{array}{c}\text { Economic } \\
\text { performance }\end{array}$ & 0.69450 & 0.21865 & 0.08685 & 0 \\
\hline Social benefits & 0.64440 & 0.25105 & 0.08285 & 0 \\
\hline
\end{tabular}


Table 9 Evaluation Results of Level 2

\begin{tabular}{cccc}
\hline excellent & good & medium & poor \\
\hline 0.71571 & 0.196642 & 0.0726228 & 0.0087492 \\
\hline
\end{tabular}

According to the principle of maximum membership degree, it can be seen from Table 9 that the value of 0.71571 is the largest in the membership degree of the four grades, so the comprehensive membership value of the project is 0.71571 , and the evaluation value is "excellent", which indicating that the experts are recognized for the project.

According to Table 8, the evaluation results are converted into scores and sorted overall. Set the comment set $\mathrm{V}=\{$ excellent, good, medium, poor $\}=\{100,80,60,40\}$. As shown in Table 10 , the technical indicators ranked first in the score of 93.017, indicating that the project reached a higher level of technology. Experts are satisfied with the economic benefits which ranked second. But the social benefits indicators compared to the previous two indicators did not have 90 points, indicating that the project should continue to enhance the social benefits and improve social responsibility. On the whole, the total score of the customer satisfaction of the power enterprise is 92.010 points, indicating that the overall level of expert evaluation of the power transmission project is good.

Table 10 Indicator Scores and Sort Results

\begin{tabular}{ccccc}
\hline Indicator & project & Technical & $\begin{array}{l}\text { Economic } \\
\text { performance }\end{array}$ & Social benefits \\
\hline score & 92.010 & 93.017 & 92.153 & 89.495 \\
\hline sequence & & 1 & 2 & 3 \\
\hline
\end{tabular}

\section{Conclusion}

This paper presents a fuzzy comprehensive evaluation method for power transmission and transformation engineering based on analytic hierarchy process. Through the comprehensive consideration of technical, economic, social and other factors, we can deal with the ambiguity of the relationship between the factors, and make a comprehensive comprehensive evaluation of the project. The evaluation method includes expert knowledge of experience, combine qualitative analysis and quantitative calculation, which can provide scientific decision-making basis for engineering staff and management personnel. The results of the fuzzy comprehensive evaluation of the $220 \mathrm{~V}$ power transmission project in Gaobeidian are consistent with the actual analysis and judgment of the project. The comprehensive evaluation method is scientific and practicable, and has practical application value and practical significance.

\section{References}

[1] Y.J Guo: Comprehensive evaluation theory, methods and development. (Beijing: Science Press, 2012). (In Chinese)

[2] X. Deng, J.M. Li, H.J. Zeng, J.Y. Chen and J.F. Zhao: Journal of Mathematics, (2012) No.7, p93-100. (In Chinese)

[3] Tan Yuejin. Quantitative Analysis Method.( Beijing: Renmin University of China Press, 2012). (In Chinese)

[4] Z.Y. Xu, X.D. Zhang and M. Z: East China Electric Power, Vol.37 (2009) No.3, p488-491. (In Chinese) 
[5] J.M. Wang, T. Shi: East China Electric Power, Vol.40 (2012) No.2, 193-196. (In Chinese)

[6] Z.W. Sun: China Science and Technology Exhibition, (2010) No.33, p633-634. (In Chinese)

[7] G.Q. Cui: China Science and Technology Information, (2011) No.16, p11 -12. (In Chinese)

[8] H. Shen: Electric Power Survey \& Design, (2013) No.8, p1-4. (In Chinese)

[9] G. Lu, W.X. Sun, X.S. Niu: Shandong Electric Power Technology, (2013) No.4. (In Chinese)

[10]F. Gao, J. Wu: Power System Protection and Control, Vol.44 (2016) No.22, p12-17. (In Chinese)

[11]S.X. Tian, H.Z. Cheng and H. Chang: Power Automation Equipment, Vol.35 (2015) No.2, p145-152. (In Chinese) 